\title{
Improving catchment runoff estimates by ameliorating the impacts of SILO pluviometer data discontinuities through expanding the SILO reference database
}

\author{
$\underline{\text { L. K. Stewart }}^{\mathrm{a}}$ and S. J. Jeffrey ${ }^{\mathrm{b}}$ \\ ${ }^{a}$ Paddock to Reef Program, Queensland Department of Resources, Australia \\ ${ }^{b}$ Land Surface Sciences, Queensland Department of Environment and Science, Australia
}

\begin{abstract}
Australian Bureau of Meteorology (BOM) pluviometer records are used to inform the SILO database of gridded Australian climate data (Jeffrey et al., 2001). The SILO gridded climate data values are generated using mathematical interpolation techniques to construct spatial grids and infill gaps in time series datasets. As such, discontinuities in the pluviometer record at a particular location, such as the initiation or cessation of a pluviometer have the potential to introduce a step change in the characteristics of interpolated rainfall estimates for nearby locations, with implications for modelled runoff and flow within catchment models.
\end{abstract}

We provide an example, relating to the Tully River catchment, North Queensland, Australia, where such discontinuities significantly impact the frequency distribution of rain-day-depth, the annual-averages of categorised rain-day-depths, and long-term trends in estimated rainfall at SILO grid-points. Secondly, we show that despite these discontinuities, runoff estimates were significantly improved with better spatial coverage of rainfall data.

The Tully River flow is modelled within the Paddock to Reef (P2R), Wet Tropics catchment model over the period July, 1986 to June, 2014 inclusive (McCloskey et al. 2021). Within the upper Tully River catchment area, rainfall observations commenced at the Sutties Creek pluviometer in 2001, and observations ceased at the Koombooloomba Dam pluviometer in 2011. In concert with the inception of the Sutties Creek pluviometer the annual average modelled flow of the Tully River post 2000 was reduced by $18.1 \%$. We show the association of pluviometer inception with sudden changes in the frequencies of categorised, estimated rain-day-depths and average annual rainfall within categorised, estimated rain-day-depths at a nearby SILO grid-point (up to a $32 \%$ reduction). Similar results are associated with the cessation of the Koombooloomba Dam pluviometer.

The large magnitude of such changes is likely due to the upper Tully catchment being primarily represented by extremely mountainous terrain, where the orographic effect will be prevalent, and few pluviometers. Thus, the initiation or cessation of a pluviometer site can influence a wide area in the SILO spatial interpolation of observed rainfall values.

To examine the value of additional pluviometer data in ameliorating the impacts of pluviometer data, discontinuities, we assessed a new set of SILO gridded rainfall estimates, constructed using observational rainfall data from an additional 466 pluviometers in the Queensland Flood Warning Network. The new SILO rainfall estimates led to an improved representation of modelled flow for the Tully River in the P2R, Wet Tropics, catchment model.

Modellers should therefore be aware of the potential impacts of pluviometer inception or cessation on rainfall interpolation and the effects on modelled runoff, particularly in regions of low pluviometer areal density.

Further study should be undertaken to investigate the benefits from using spatial rainfall estimates constructed using pluviometer data collected by individuals, groups or organisations in addition to the Bureau of Meteorology, versus the increased uncertainty due to the potentially lower quality standards employed in the collection of such data.

Keywords: SILO, rainfall, interpolation, modelling, flow 


\section{INTRODUCTION}

SILO provides spatio-temporal climate datasets for Australia, including gridded estimates of rainfall and gapfilled timeseries data sets for pluviometer locations. These estimates are produced using mathematical interpolation techniques (Queensland Government, 2020). SILO gridded data are used as rainfall inputs for various environmental modelling activities (e.g., Siriwardena et al., 2006; McCloskey et al. 2021).

SILO estimates rely upon rainfall records primarily from Bureau of Meteorology (BOM) pluviometers that meet certain quality control criteria. SILO's interpolated estimates are constructed by spatially interpolating the data available for the given day (or period) and consequently, the accuracy is strongly dependent on the quality of the data and the location and density of the recording stations. The pluviometer network is constantly evolving as stations are initiated, closed, or are temporarily unavailable due to site maintenance. The quality of the data may be influenced by site factors (leading to systematic bias), and random errors (such as operator error). In the case of historic data, error detection may be done many years after the data were collected.

Consequently, the interpolated estimates are constructed from datasets which are surprisingly dynamic, and this may have profound implications for model calibration. For example, consider a coastal location where there are two permanent rain gauges: one is located on the top of a mountain (receiving relatively high rainfall due to orographic effects) and the other is located some distance away on the leeward side (where it receives significantly lower rainfall). In this situation, the interpolated datasets would typically overestimate the rainfall at the base of the mountain on the leeward side. If a new recording station was installed in this area, the interpolation bias would be immediately reduced for the period over which the new station was operational. It is important to be aware that the dynamic nature of the observed data and station network can result in abrupt changes to the characteristics of interpolated datasets.

As a part of the P2R program, a modified eWater Source (eWater, 2012) modelling framework is used to model runoff, fine sediment, particulate and dissolved nutrient generation, loss, and transport processes for the six NRM regions that make up the GBR catchments (McCloskey et al. 2021). The Wet Tropics catchment model simulates a 28 -year period (July 1986 - June 2014 inclusive). Quality assessment of model output identified an abrupt decline in the quality of fit between monitored and modelled annual flow for the Tully River at Euramo (Fig. 1) commencing around the year 2000 (Fig. 2). Suspicion for this result fell to either the quality of the flow gauging or rainfall input data. An investigation excluded the former possibility and so the SILO gridded rainfall estimates then became the focus of further study.

It was found that within the time frame of interest the BOM pluviometer at Koombooloomba Dam, 031083, (BOMb, 2020), located in the mountainous

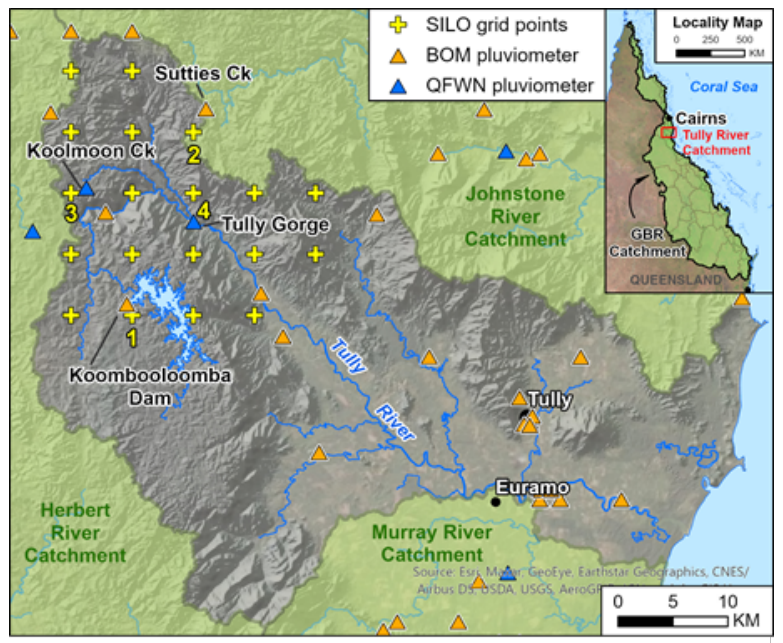

Figure 1. Location of the Tully catchment, Wet Tropics region. Important pluviometer locations are named and SILO grid-points GP1, GP2, GP3, and GP4 are annotated "1", "2", "3", and "4", respectively (see text). upper-Tully catchment, ceased to operate in December 2011. The SILO grid-point, referred to here as GP1, $\left(17.85^{\circ} \mathrm{S}, 145.6^{\circ} \mathrm{E}\right)$ is located approximately one kilometre from the Koombooloomba Dam pluviometer site (Fig. 1).

Additionally, the BOM pluviometer at the Sutties Creek site, 031186, (BOMc, 2020) began recording in the year 2001. The SILO grid-point, referred to here as GP2 $\left(17.7^{\circ} \mathrm{S}, 145.65^{\circ} \mathrm{E}\right)$ is located two kilometres from the Sutties Creek pluviometer site (Fig. 1).

The impact that the initiation and cessation of these data point-sources had on the consistency of the trend in estimated cumulative rainfall, and the frequency distribution of SILO-estimated daily rainfall is examined for GP1 and GP2 and considered in the context of the noted anomaly in modelled flow post 2000. 


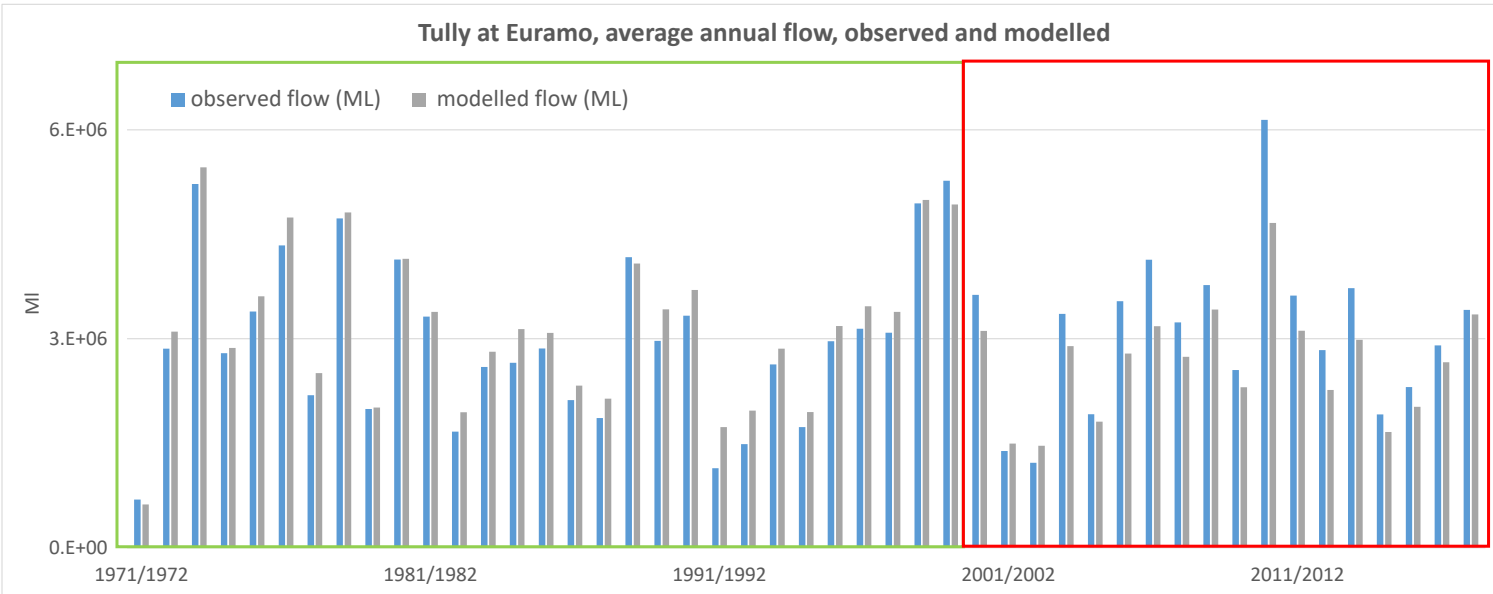

Figure 2. Plot of modelled and observed flow for the Tully River at Euramo. An abrupt change in the fit between modelled and observed flow is evident from approximately the year 2000. Prior to that date the modelled flow generally exceeded observed flow, while post 2000 the opposite is true.

Spatial variability of rainfall can be very high and thus difficult to capture via an interpolation process (Evans et al., 2020). The situation can be theoretically improved by increasing the density of pluviometers whose data is used to produce the rainfall estimates (e.g., Andiego et al., 2018; Gyasi-Agyei, 2020). The Queensland Department of Environment and Science maintain the SILO database and have been proactively developing a new version that utilises the data of approximately 460 additional pluviometers that form the Queensland Flood Warning Network, subsequently referred to herein as SILOQ. Two of these additional pluviometers lie in the upper-Tully catchment (Koolmoon and Tully Gorge). The SILO grid-points referred to herein as GP3 (17.7 $\left.{ }^{\circ} \mathrm{S}, 145.65^{\circ} \mathrm{E}\right)$ and GP4 $\left(17.75^{\circ} \mathrm{S}, 145.65^{\circ} \mathrm{E}\right)$ are located approximately one kilometre and two and a half kilometres from the Koolmoon and Tully Gorge pluviometer sites, respectively.

We examine the influence of SILOQ data in the context of temporospatial improvement in estimated rainfall in the upper-Tully and concomitant improvement in modelled versus monitored flow.

\section{Methods}

\subsection{Impact of pluviometer inception and cessation}

The consistency of SILO estimated rainfall at GP1 and GP2 over time was assessed by examining the relative frequencies of daily, estimated rainfall-depths falling within $>0$ to $10 \mathrm{~mm},>10$ to $20 \mathrm{~mm},>20$ to $30 \mathrm{~mm},>30$ to $40 \mathrm{~mm}$, and $>40 \mathrm{~mm}$ ranges using a rolling, seven-year window. A seven-year window was chosen to minimise the effects of interannual variability on frequency counts and to be shorter than the period of record post removal of the Koombooloomba Dam pluviometer.

Plots of cumulative, estimated daily rainfall for GP1 and GP2 were assessed for any changes in long term trend that may be indicative of a significant change in estimated daily rainfall with time. Annual average estimated rainfall, within the previously mentioned rain-day depth categories, was calculated pre and post any noted changes in cumulative rainfall trend to assess the impact on rainfall characteristics.

\subsection{Assessment of SILOQ}

A total of 19 SILO grid points across the upper-Tully catchment were identified and both SILO and SILOQ daily rainfall estimates extracted from the relevant database. The daily rainfall estimates for each grid-point were summed across 1970 to 2020 , for both sets, and the results compared to establish the difference in rainfall volume at each location.

The introduction of additional pluviometer sites at Koolmoon and Tully Gorge also presented the opportunity to assess how well the original SILO, and SILOQ, rainfall estimates at GP1 and GP2 compare to observed rainfall. This was achieved by calculating annual average estimated-rainfall within the previously mentioned rain-day depth categories.

Tully River flow is monitored at Euramo (113006A, Fig. 1)) The Wet Tropics P2R catchment model was run using each set of daily rainfall estimates and the impact on the quality of fit between monitored and modelled 
flow at the Euramo quantitatively assessed. Using the original SILO estimated rainfall dataset in simulations the modelled flow generally exceeds observed up to the year 2000 and the opposite is true after that date. Therefore, we use the difference of mean error between modelled and observed flow for each those periods as a measure of improvement.

\section{Results}

\subsection{Impact of pluviometer inception and cessation}

\subsubsection{Pluviometer cessation, GP1}

Frequency analysis of GP1 estimated rainfall indicates a step change (evident via a linear 7-year transition) in the relative frequencies of estimated daily rainfall values from pluviometer cessation in December 2011 (Fig. 3a,b. In addition, there appear to be some rain-depth frequency changes associated with the post 1998 period in which observed data quality was lower.

(a)

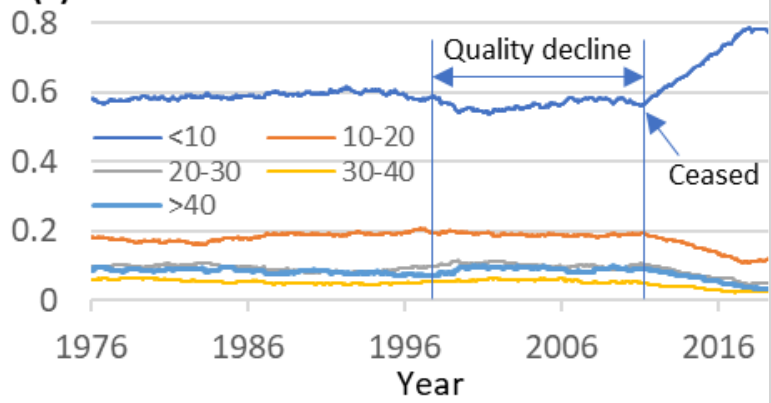

(b)

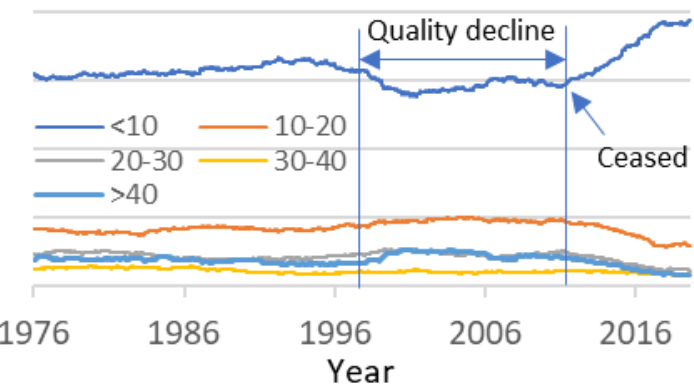

Figure 3. Plots of rain-day relative frequency (seven-year rolling window) for rain-day depth categories $<10 \mathrm{~mm}, 10$ to $<20 \mathrm{~mm}, 20$ to $<30 \mathrm{~mm}, 30$ to $<40 \mathrm{~mm}$ and $>=40 \mathrm{~mm}$. "Ceased" indicates pluviometer cessation, and "Quality decline" a period of reduced data quality. (a) Koombooloomba Dam PPD data, and (b) SILO grid-point GP1. The linear change in frequencies over a seven-year period post pluviometer removal is indicative of a step change in rain-day frequency, given the seven-year rolling window.

This is also evident in the plot of the change in annual average estimated rainfall pre to post pluviometer cessation (Fig. 4a). The plot of cumulative rainfall for GP1 (Fig. 4b) shows a distinct break in trend in 2011 indicating a sudden change in the accumulation rate of estimated daily rainfall from the time that the Koombooloomba Dam pluviometer ceased operating. The smaller changes in relative frequency from 1998 do not appear to have impacted the cumulative rainfall trend.
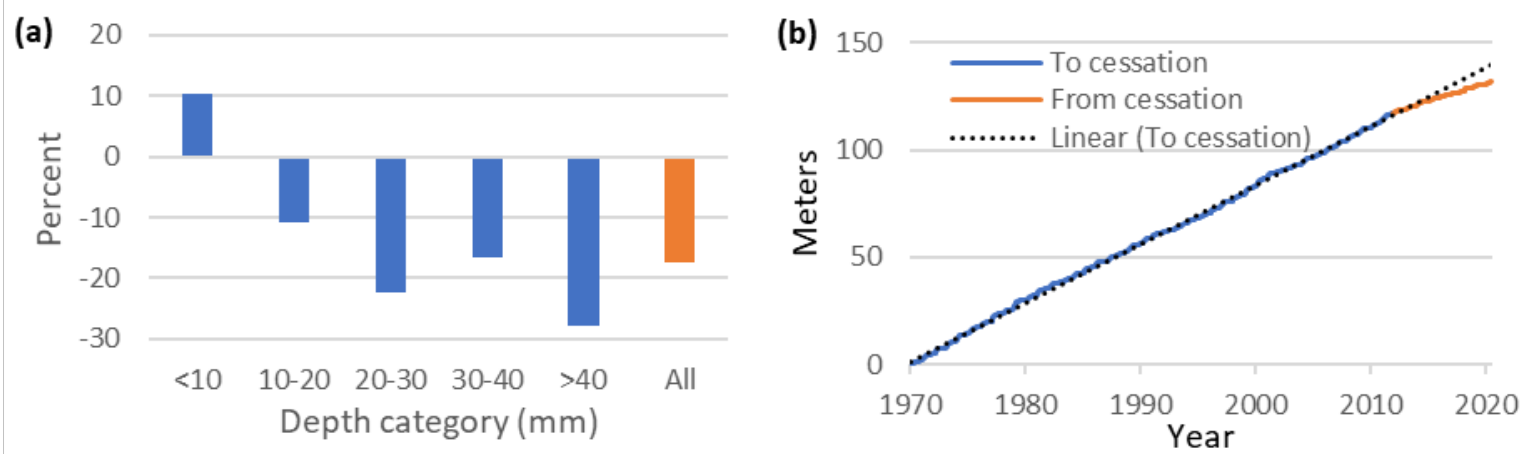

Figure 4. (a) Change in average annual estimated rainfall at GP1, within each rain-day depth category, pre to post Koombooloomba Dam pluviometer cessation. (b) Cumulative plot of SILO estimated rainfall at GP1.

The direction of change in the categorised average-annual-rainfall is consistent with the changes in relative frequency of rain days shown in figure 4. Figures 3 and 4 show that the removal of the pluviometer at Koombooloomba Dam resulted in distinct changes in the characteristics of the estimated rainfall and reduced the frequency, and average annual depth, of runoff producing falls. For example, the average annual depth of falls greater than $40 \mathrm{~mm}$ fell $28 \%$ from $1150 \mathrm{~mm}$ to $829 \mathrm{~mm}$ ). 


\subsubsection{Pluviometer inception, GP2}

Frequency analysis of GP2 estimated rainfall values also revealed changes in frequencies of rain-days from the inception of the Sutties Ck. pluviometer in 2001. Plots of the change in average annual estimated rainfall within each rain-day depth category (Fig. 5a) and cumulative SILO estimated daily rainfall (Fig. 5b) indicate a distinct change in rainfall characteristics from the pluviometer inception in 2001.
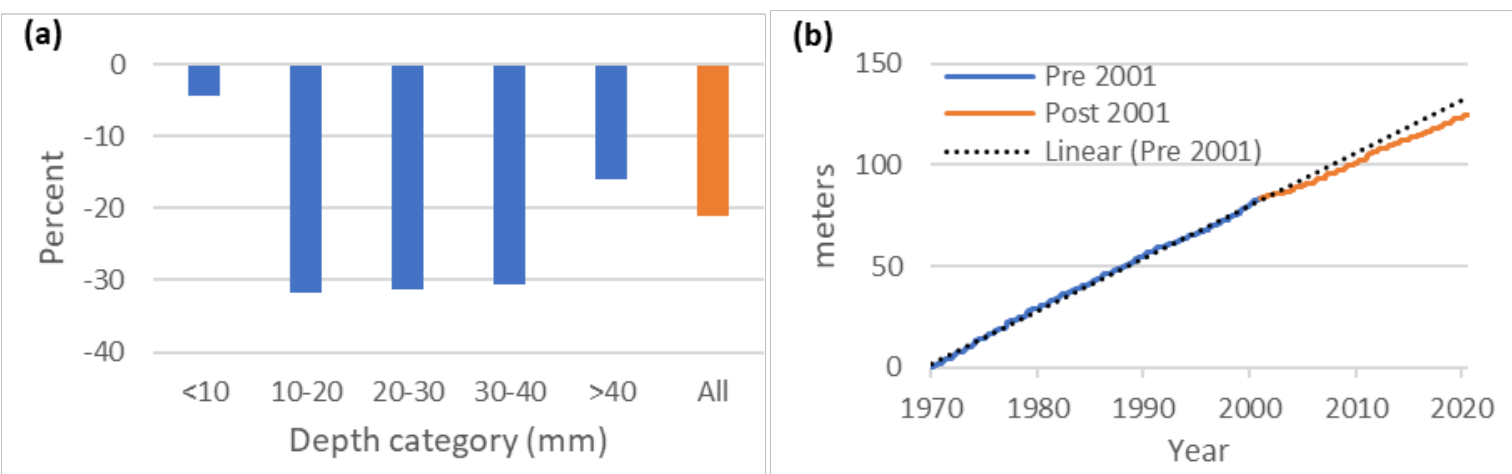

Figure 5. (a) Change in average annual estimated rainfall at GP2, within each rain-day depth category, pre to post Sutties Creek pluviometer inception in 2001, and (b) cumulative plot of estimated rainfall at GP2.

Observation data records for Kareeya (031085, upper-Tully, ) and Tully Sugar Mill (032042, lower-Tully) are largely complete and provide a useful comparison to the discontinuous records. Cumulative rainfall plots for the PPD data for each of these locations indicate no change in rainfall characterisitics pre to post 2000 (Fig. $6 a, b)$. This suggests that similar results might be expected from other sites in the Tully catchment.
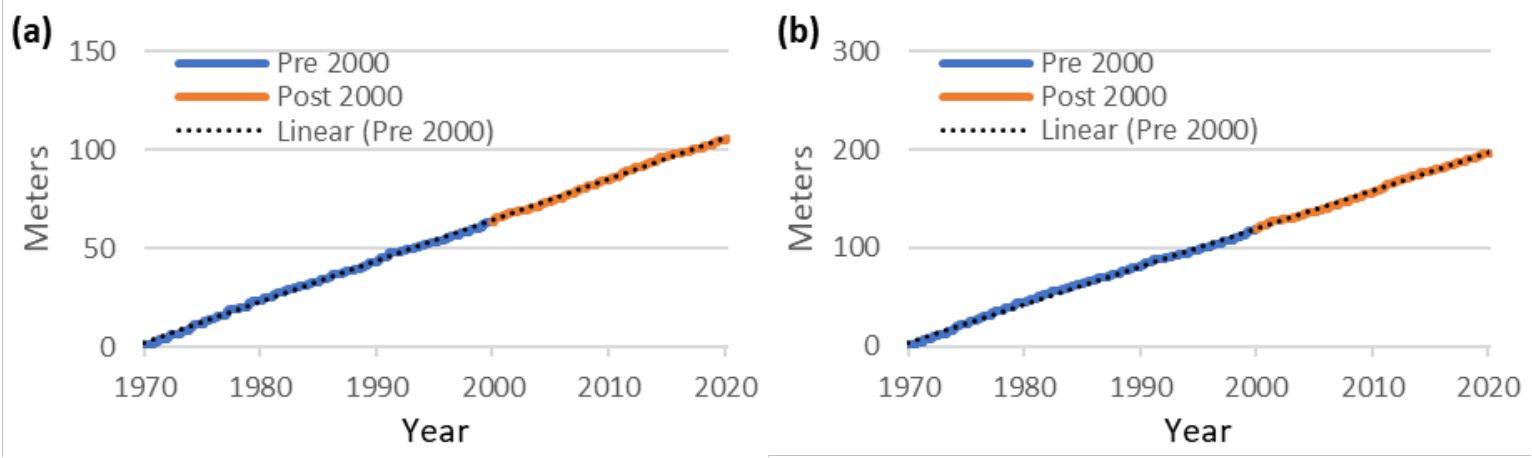

Figure 6. Cumulative plots of SILO PPD rainfall at (a) Kareeya, upper Tully, and (b) Tully Sugar, lower Tully. Both pluviometers have reasonably complete rainfall records.

\subsection{Assessment of SILOQ}

Figure 1 shows the location of the 19 SILO grid points across the upper-Tully catchment for which the total rainfall over the period 1/1/1970 to 31/7/2020 was calculated for both the SILO and SILOQ estimated-rainfall datasets.

The largest increases in estimated total rainfall correspond to grid-points closest to the locations of Queensland Flood Warning Network pluviometers whose data were incorporated into the interpolation to produce the SILOQ rainfall estimates. The average increase in estimated rainfall across the 19 SILO grid-points was 5 percent. The largest increase in estimated rainfall was 23\% at GP3 near the Koolmoon pluviometer.

In Figure 7 we compare annual average rainfall and rain-day depth categories computed using estimated (SILO and SILOQ) rainfall at grid-points GP3 \& GP4, and observed rainfall at the closest QFWN pluviometers (Koolmoon and Tully Gorge, respective). The results suggest that volume and spatial variability of rainfall in the upper-Tully catchment is not well represented in the SILO rainfall estimates. The SILOQ results for those grid-points show a considerable increase in estimated rainfall, particularly in the categories corresponding to larger, runoff-producing falls. 
(a)

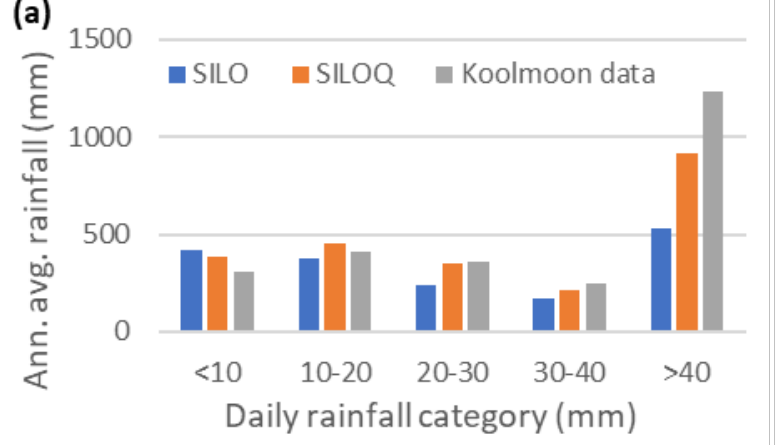

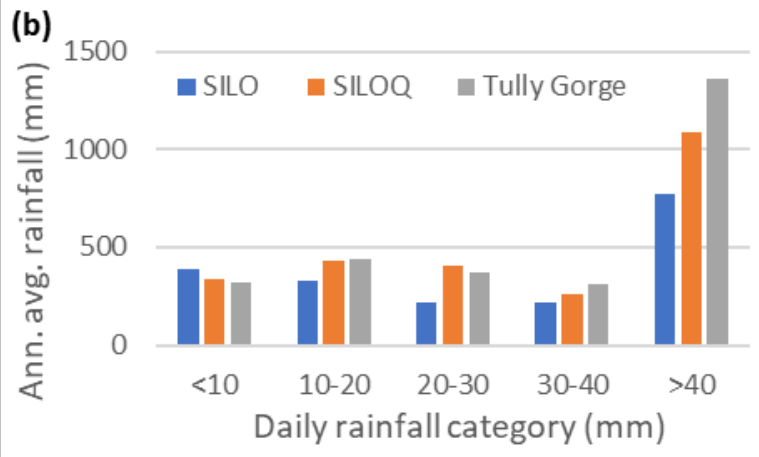

Figure 7. Categorised average annual rainfalls for pluviometer data and SILO and SILOQ estimates at nearby grid-points. (a) Koolmoon and (b) Tully Gorge.

The improved representation of rainfall within the upper catchment using SILOQ data resulted in a better match between modelled and observed flow pre and post 2000 for the Tully River at Euramo (Fig. 8), as compared to using the original SILO estimates. However, the abrupt decline in quality of fit between pre and post 2000, while reduced in magnitude, was still present.

\section{Discussion}

The results indicate that the inception or cessation of a pluviometer can profoundly affect the characteristics of interpolated rainfall in the surrounding area, as indicated by metrics such as

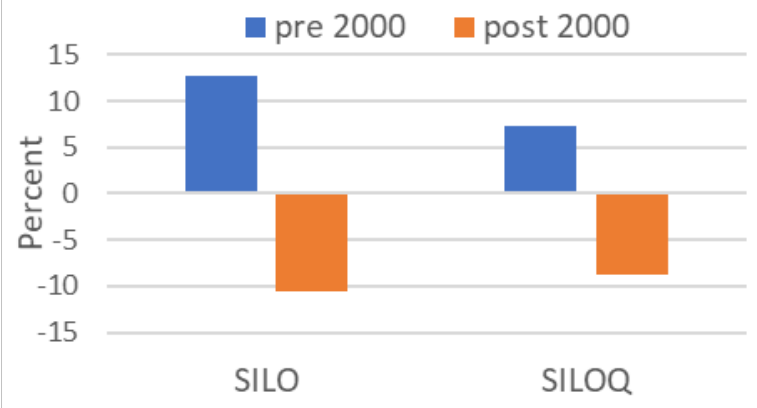

Figure 8. Percent difference between modelled and observed flow, pre and post 2000 , for simulations using SILO and SILOQ rainfall. categorised rain-day depth frequencies, categorised annual average rain-day depth totals, and long-term trend in cumulative, estimated daily rainfall. The inception and cessation of the upper-Tully pluviometers studied here resulted in decreases in annual-average estimated rainfall in rain-day depth categories greater than $10 \mathrm{~mm}$. This change was reflected in the break of the longterm trend in cumulative estimated daily rainfall. The Koombooloomba Dam pluviometer cessation produced a profound shift in estimated rain-day-depth frequencies toward smaller falls. The pluviometer initiation at Sutties Creek resulted more in a reduction of the magnitude of falls at GP2, rather than rain-day-depth relativefrequency changes.

When using a catchment model, care should be taken to understand the impact of discontinuities in interpolated reference rainfall records. Discontinuities in those records may result in sudden changes in the long-term characteristics of rainfall estimates. These have the potential to lead to sudden changes in modelled runoff across the area of influence of the pluviometer data. For example, we noted reductions of $18 \%$ and $21 \%$ in average annual estimated rainfall at GP1 and GP2, respectively. While these reductions will not be indicative of changes in estimated rainfall over the entire upper Tully catchment, we have shown that the discontinuity in Sutties Creek pluviometer data correlates with a $18.1 \%$ reduction in modelled flow near the end of system.

The upper-Tully is comprised primarily of mountainous National Park areas and is sparsely populated with BOM pluviometers. The Sutties Creek pluviometer is the only instrument within an area of approximately 345 square kilometres. Thus, data from that location may locally dominate in the SILO interpolation yet not be representative of the wider rainfall distribution.

Increasing pluviometer areal density by the addition of the QFWN pluviometers into the SILO interpolation ameliorated the impact of pluviometer data discontinuities by improving the representation of modelled flow, pre and post 2000, for the Tully River. The error between annual values of observed and modelled flow at the Euramo gauge, pre and post 2000 , from $12.6 \%$ to $7.25 \%$ and $-10.5 \%$ to $-8.7 \%$, respectively (Fig. 8 ). In addition, 
the $18.1 \%$ deficit in modelled flow was reduced to $15.9 \%$. Unfortunately, neither of the two additional QFWN pluviometers located in the upper-Tully were within $10 \mathrm{~km}$ of the Sutties Creek pluviometer, which is likely to be influencing estimated rainfall over a large domain.

While the QFWN station network may use pluviometers which differ from those used by the BOM, and be located and managed to different operating protocols, they provide valuable rainfall information that appears to improve the spatial representation of estimated rainfall and thus modelled flow. In the context of interpolated rainfall estimates it would be useful to examine the relationship between the use of observational data collected from a range of instruments and operating agencies, with the reduction in interpolation error through increased pluviometer areal density.

In conclusion, we recommend that modellers utilising grided/interpolated estimated rainfall data be aware that discontinuities in reference pluviometer records may result in large and sudden changes in runoff response and modelled runoff and that the overall magnitude of such changes may be reduced by increasing pluviometer areal density.

\section{REFERENCES}

Andiego, G. , Waseem, M. , Usman, M. and Mani, N. (2018) The Influence of Rain Gauge Network Density on the Performance of a Hydrological Model. Computational Water, Energy, and Environmental Engineering, 7, 27-50. doi: 10.4236/cweee.2018.71002.

Australian and Queensland government, 2021. Reef 2050 Water Quality Improvement Plan. Paddock to Reef Reef 2050 Water Quality Improvement Plan (reefplan.qld.gov.au)

BOMa, Quality control of climate Data. dwww.bom.gov.au/climate/data-services/content/qualitycontrol.html

BOMb, 2020. Basic Climatological Station Metadata, Koombooloomba Dam.

http://www.bom.gov.au/clim_data/cdio/metadata/pdf/siteinfo/IDCJMD0040.031083.SiteInfo.pdf

BOMc, 2020. Basic Climatological Station Metadata, Sutties Creek Alert.

http://www.bom.gov.au/clim_data/cdio/metadata/pdf/siteinfo/IDCJMD0040.031186.SiteInfo.pdf

eWater, L, 2012. Source Catchments Product Information. eWater Ltd.

Evans, A., Jones, D., Smalley, R., and Lellyett, S., 2020. An enhanced gridded rainfall analysis scheme for Australia. Bureau of Meteorology, Bureau Research Report - BRR041.

http://www.bom.gov.au/research/publications/researchreports/BRR-041.pdf

Gyasi-Agyei, Y. Identification of the Optimum Rain Gauge Network Density for Hydrological Modelling Based on Radar Rainfall Analysis. Water 2020, 12, 1906. https://doi.org/10.3390/w12071906

Jeffrey, S. J., Carter, J.O., Moodie, K.W., and Beswick, A.R., 2001. Using spatial interpolation to construct a comprehensive archive of Australian climate data. Environmental Modelling and Software, 16, 309-330.

McCloskey, G.L., Baheerathan, R., Dougall, C., Ellis, R., Bennett, F.R., Waters, D., Darr, S., Fentie, B., Hateley, L., Askildsen, M., 2021. Modelled estimates of fine sediment and particulate nutrients delivered from the Great Barrier Reef catchments. Marine Pollution Bulletin, 165.

Queensland Government, 2021. SILO. SILO | LongPaddock | Queensland Government

Siriwardena, L., Finlayson, B.L., McMahon, T.A., 2006. The impact of land use change on catchment hydrology in large catchments: The Comet River, Central Queensland, Australia. Journal of Hydrology, 326, 199-214. 